\section{$\checkmark$ DOE/SF/19/68-T3}

HAWAII ENERGY STRATEGY PROGRAM

Annual Report 1993

This is the second annual report on the Hawaii Energy Strategy (HES) program which began on March 2, 1992, under a Cooperative Agreement (DE-FC0392F19168) with the United States Department of Energy (USDOE). The HES program is scheduled for completion by December 31, 1994. As outlined in the Statement of Joint Objectives:

The purpose of the study is to develop an integrated State of Hawaii energy strategy, including an assessment of the State's fossil fuel reserve requirements and the most effective way to meet those needs, the availability and practicality of increasing the use of native energy resources, potential alternative fossil energy technologies such as coal gasification and potential energy efficiency measures which could lead to demand reduction. This work contributes to the (US)DOE mission, will reduce the State's vulnerability to energy supply disruptions and contributes to the public good.

The seven projects of the HES program are designed to increase understanding of Hawaii's energy situation and to produce recommendations to achieve the State energy objectives of dependable, efficient, and economical statewide energy systems capable of supporting the needs of the people, and increased energy self-sufficiency.

Hawaii's Energy Problem. Hawaii depends on imported oil for over $92 \%$ of its energy. This makes Hawaii the most vulnerable state in the Nation to the disruption of its economy and way of life in the event of a disruption of the world oil market or rapid oil price increases. Currently, $40 \%$ of Hawaii's oil comes from Alaska and the remainder from the Asia-Pacific region. The export capabilities of these domestic and foreign sources of supply are projected to decline by approximately $50 \%$ by the year 2000 . This will likely increase Hawaii's dependence on the oil reserves of the politically unstable Middle East.

Hawaii is also vulnerable to possible supply disruptions in the event of a crisis. The long distance from the U.S. Strategic Petroleum Reserve in Louisiana and Texas, combined with a declining number of U.S.-flag tankers capable of transiting the Panama Canal, make timely emergency deliveries problematic.

Environmental protection is also a major concern for Hawaii and its residents. Energy production from fossil fuels is the major source of local and global air pollutants, while petroleum shipping and handling pose risks to fragile marine habitats and coastal resort areas. An energy policy which internalizes the environmental and social costs of fossil fuels will place added value on energy

\title{
DISCLAIMER
}

This report was prepared as an account of work sponsored by an agency of the United States Government. Neither the United States Government nor any agency thereof, nor any of their employees, makes any warranty, express or implied, or assumes any legal liability or responsibility for the accuracy, completeness, or usefulness of any information, apparatus, product, or process disclosed, or represents that its use would not infringe privately owned rights. Reference herein to any specific commercial product, process, or service by trade name, trademark, manufacturer, or otherwise does not necessarily constitute or imply its endorsement, recommendation, or favoring by the United States Government or any agency thereof. The views and opinions of authors expressed herein do not necessarily state or reflect those of the United States Government or any agency thereof.
HES94-1:Annual Report 1993

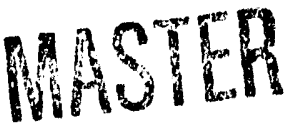


efficiency and renewable energy and could resu't in an increase in the market price of energy to consumers.

Hawaii's Energy Potential. Hawaii has significant, yet relatively untapped, renewable energy resources and energy- efficiency potential. Biomass, wind, solar, geothermal, hydroelectric, and ocean thermal and wave resources can provide clean, stable sources of energy supply. The Islands' energy savings potential would likely allow utilities to defer construction of additional fossil fuel-fired power plants by reducing electricity demand through conservation and increased energy efficiency. Efficiency gains in the transportation sector are also possible.

Hawaii Energy Strategy Goals. The HES is designed to achieve the following program goals:

- Increased diversification of fuels and sources of supplies of these fuels;

- Increased energy efficiency and conservation;

- Development and implementation of regulated and non-regulated energy development strategies with the least possible overall cost to Hawaii's society;

- Establishment of a comprehensive energy policy analysis, planning, and evaluation system;

- Increased use of indigenous, renewable energy resources; and

- Enhanced contingency planning capability to effectively contend with energy supply disruptions.

Hawaii Energy Strategy Benefits. The HES will assist State of Hawaii planners and policy makers, and other members of the Hawaii energy community, in better understanding Hawaii's current energy situation, developing and analyzing possible future energy scenarios, and determining a preferred energy future for Hawaii.

The HES will provide a comprehensive and integrated system for:

- Energy resource data and technology acquisition, assessments, analyses, and forecasting;

- $\quad$ Energy policy analysis and evaluation; and

- Energy planning, plan implementation and evaluation. 
The integrated strategy will also be useful for regional planning analyses and federal analyses by the USDOE. Federal policies, embodied in the National Energy Strategy, can be tested and evaluated at the state level. Hawaii represents an ideal candidate for such analyses because its geographic isolation allows policy makers to readily track energy flows, given the right analytical tools and data.

\section{THE PROJECTS OF THE HAWAII ENERGY STRATEGY PROGRAM}

There are seven projects in the HES program:

Project 1: Analytical Energy Forecasting Model;

Project 2: $\quad$ Fossil Energy Review and Analysis;

Project 3: Renewable Energy Resource Assessment Development Program;

Project 4: Demand-Side Management Assessment;

Project 5: Transportation Energy Strategy;

Project 6: Energy Vulnerability Assessment Report and Contingency Planning; and

Project 7: $\quad$ Energy Strategy Integration and Evaluation System.

This section describes the accomplishments of each of the HES projects during 1993 in detail.

\section{PROJECT 1: ANALYTICAL ENERGY FORECASTING MODEL FOR THE STATE OF HAWAII}

Project 1 Purpose and Objectives. Project 1 was completed in 1993. It developed the capability for the State of Hawaii to conduct comprehensive energy assessments, forecasts, and analyses.

Project 1 objectives were as follows:

- $\quad$ Establish a computerized model for energy forecasting and assessment capable of projecting the demend for energy over a time horizon of at least 20 years under a variety of different scenarios dealing with the level and mix of economic activity, energy prices, technological change, regulatory standards, and utility demand-side management (DSM) programs; 
- Develop a data gathering and management system to support the energy forecasting and assessment system; and

- $\quad$ Conduct training to develop State staff expertise in using and updating the analytical energy forecasting model.

Project 1 Accomplishments. Barakat \& Chamberlin, Inc. (BCI), was selected as the project consultant by a competitive bid process in February 1992 . Work began in April 1992 and the ENERGY 2020 model was selected for the project in October 1992.

In January 1993, meetings were held to define the residential, commercial, industrial, and transportation energy use sectors in Hawaii for use in the ENERGY 2020 model. The meeting also shared transportation sector modeling ideas and data with the Project 5 (Transportation Energy Strategy) team. Agreement was reached on a basic model structure that would disaggregate ground transportation demand by county and aggregate aviation, marine, and military transportation demands to the state level.

Also during the first quarter of 1993, the consultants completed acquiring and modifying the ENERGY 2020 model for Hawaii's residential, commercial, industrial, and transportation energy sectors; identified data requirements; and developed a data reporting format.

The State of Hawaii Department of Business, Economic Development \& Tourism (DBEDT) Energy Division purchased an IBM-compatible 486DX66 computer with a math co-processor, $8 \mathrm{MB}$ RAM, and a $212 \mathrm{MB}$ hard drive for use in running the ENERGY 2020 model. The ENERGY 2020 model was installed on the new machine.

Significant progress was made on the development of the ENERGY 2020 forecasting model in the second quarter. During April, BCI and its subcontractor, Systematic Solutions, Inc. (SSI), finished compiling and preparing data inputs, and generated the first series of trial forecasts with the model.

The results of this research were presented to Energy Division staff, utility staff, and other interested parties in a series of meetings from May 12 through 14. These meetings initiated the process of evaluating the model and its forecasts, establishing priorities for refinement, and refining the model and data inputs.

One important outcome of the May meetings was the identification of the need for more gas industry-specific billing data for Oahu and billing data for all fuels from all islands, except Oahu, to calibrate and improve the model.

By the end of the third quarter, most of the demand sectors of the model were complete. A change was made in the model to prepare it for use in the future 
integrated energy system model which is being developed under HES Project 7 (Integration and Evaluation System). This involved building a separate forecasting model for each of Hawaii's counties. This greater level of detail will assist in evaluating policy option impacts at the county level.

Project 1 will be completed in early 1994 . The final calibration of the demand module of ENERGY 2020 will be completed and the model results will be presented to the Energy Division staff in the second week of January. The Energy Division staff will also receive training on the operation of the model.

\section{PROJECT 2: FOSSIL ENERGY REVIEW AND ANALYSIS}

Project 2 Purpose and Objectives. Project 2 conducted a comprehensive Hawaii and Pacific area fossil energy review and analysis. The project examined oil, gas, and coal opportunities in Hawaii. The project met its objective of obtaining a clearer understanding of fossil energy use in Hawaii for use in conducting comprehensive energy assessments, forecasts, and analyses. The project also investigated the possible additional use of coal in Hawaii and the changes needed in infrastructure, the costs of changes, and possible economic and environmental impacts.

Project 2 Accomplishments. The East-West Center (EWC) Energy Program, with Argonne National Laboratory as its subcontractor, was selected as technical support consultant for this project in June 1992 and work began that July.

In the first quarter of 1993, the drafts of five chapters comprising the Overview of Fossil Fuels were delivered. This work was delayed slightly from anticipated completion at the end of 1992 due to difficulties encountered in acquiring necessary data. These chapters included:

I. Fossil Energy Characteristics;

II. The World Oil Industry;

III. The World Natural Gas Industry:

IV. The World Coal Industry; and

V. Environmental Trends Affecting Fossil Fuel Use.

The Project Manager reviewed the work and provided copies to the Fossil Fuels/Renewables Technical Review Subcommittee of the Energy Policy Advisory Committee's (EPAC) Integration Group (IG) for further review by members of Hawaii's energy community. Copies were also provided to Mr. Richard Dye, the USDOE project manager. Comments and suggestions were forwarded to the consultant for incorporation into revisions. This pattern of obtaining comment was used with subsequent drafts throughout the year. 
In addition, the consultant presented two white papers on Energy Data Issues and Oil Market Information: Hawaii State Needs. The papers suggested actions the State of Hawaii will need to take to improve the availability and quality of data necessary to monitor and evaluate the energy situation in Hawaii.

The second quarter began with a change in the EWC's Principal Investigator. Dr. David Isaak left the Center to pursue business interests. He was ably replaced by Dr. Nancy Yamaguchi, who had previously served on the Project as a Fellow.

At the end of May, EWC and the DBEDT Energy Division co-sponsored a twoday public seminar on Fossil Energy in Hawaii. The seminar was held at the EWC's Hawaii Imin International Conference Center. The seminar was designed to accomplish Project objectives of providing training to Energy Division staff and to obtain feedback and participation from the general public. About 150 people attended.

The first day of the seminar presented findings from Overview of Fossil Fuels, plus interim findings from Fossil Energy in Hawaii, and Greenfield Options: Coal Technologies. The second day of the seminar concentrated on panel presentations and discussions of the relationships between fossil energy, the economy, and the environment in Hawaii. The panels were composed of representatives from private sector energy companies, the local electric utility, environmental and civic organizations, government agencies, and the local banking community.

The Energy Division Project 2 Manager organized another data coordination meeting in early June to work out discrepancies and gaps in key data. The Energy Division Project 1 (Analytical Energy Forecasting Model) Manager, Project 5 (Transportation Energy Strategy) Manager, EWC consultants for Project 2, the DBEDT statistician, the new Energy Division statistician, and Project 5 consultants attended. Severe limitations in data available on energy and electricity end uses were encountered. As a result, the EWC scaled back the level of detail from what it originally thought would be needed. Data used in Task II had to be in aggregated form and at a relatively low level of resolution.

In mid-June, the bulk of Greenfield Options: Coal Technolo-gies, was delivered by the subcontractor, Argonne National Laboratory. This work included a report, Assessment of Coal Technology Options and Implications for the State of Hawaii, as well as a spreadsheet model specially designed by Argonne to assist the DBEDT Energy Division in calculating costs and benefits of various electricity generation technologies. The default data values in the spreadsheet can be modified by the user, creating a very useful analytical tool.

At the end of June, the first draft of Fossil Energy in Hawaii, was completed. The report covered the following key areas in its four sections: 
I. Current Fossil Energy Utilization Patterns and Trends;

II. Fossil Fuel Imports;

III. Substitutability of Fuels; and

IV. "Energy Security": Possible Frameworks.

In July, the major accomplishment was the joint Energy Division-EWC development of scenarios for Hawaii's possible energy futures, 1994-2014, for further analysis. The agreed scenarios were as follows:

a. Scenario 1, Base Case. Projection of current trends and current utility and refinery plans for fossil energy use.

b. Scenario 2, Aggressive Diversification Plan. The scenario is based upon the following assumptions:

- In the power sector, by 2010, DSM achieves a $6 \%$ demand reduction and all new generating capacity is coal based, except that renewable energy provides $10 \%$ of electrical generation.

- In the ground transportation sector, by 2010 , conventional gasoline is displaced $10 \%$ by alcohol fuels/blends, $5 \%$ by propane, and $10 \%$ by electric vehicle. Electric vehicles will be recharged at off-peak hours.

- In the air transport sector, no major changes are expected during the analysis period.

c. Scenario 3, East-West Center Optimum. This scenario presented the EWC's view of the optimum use of fossil energy in Hawaii over the coming 20 years.

In August, significant progress was made toward the construction of a linear program (LP) model designed to simulate Hawaii's oil refining and trade activity. This LP model was the chief analytical tool used in the scenario analysis in Task 4. The LP model, tentatively named "HAWMOD", simulates crude oil purchasing decisions, refinery operations, product blending, and import/export behavior to balance supply and demand, and to maximize profits and efficiency. It was calibrated in September.

The model uses a great deal of data: historical crude inputs and product outputs, future crude prices and availability by crude stream, product demand by product, product pricing in external markets (such as Los Angeles and Singapore), shipping costs for crudes and products, and petroleum product quality specifications. 
Where possible, the EWC effort tried to incorporate relevant data and forecasts from other HES activities. However, since the EWC report was one of the first completed, not all relevant and complete data sets and forecasts were available. As a result, the EWC team prepared forecasts of petroleum product demand, external market prices of crudes and products, market availability of crudes, and shipping rates, 1994-2014. This forecast data was made available to the other projects as needed.

The Project 2 final report was completed and delivered in December.

\section{PROJECT 3: RENEWABLE ENERGY RESOURCE ASSESSMENT AND DEVELOPMENT PROGRAM}

Project 3 Purpose and Objectives. One of the goals of the HES program is to increase the use of indigenous, renewable energy resources. Project 3 is working to produce a comprehensive assessment of Hawaii's renewable energy resources (wind, solar, biomass, hydroelectric, ocean thermal energy, and wave energy) and prepare a long-range strategy for developing them. The project will refine and build upon the previously completed renewable energy work in Hawaii by establishing the resource- and technology-specific potential contributions renewables can make to Hawaii's energy mix.

The project's work is divided into three phases. Phase I is to develop a renewable energy resource plan. Phase I project objectives include:

- Identify areas with renewable energy resource potential and analyze land use, ownership, and availability;

- Identify constraints to renewable energy development and eliminate areas with existing or planned competing uses;

- Conduct analysis of existing infrastructure and utility compatibility;

- Identify existing monitoring sites and equipment, additional sites, and prioritize; and

- $\quad$ Conduct a preliminary evaluation of public acceptance and environmental, visual, and cultural impacts.

In Phase II, the project will develop renewable energy resource supply curves. Specific objectives include:

- Compile cost and performance data on renewable energy conversion systems; 
- $\quad$ Analyze and reduce existing renewable energy resource data and publish Hawaii Sugar Planters' Association solar data collected since 1975; and

- Develop renewable energy resource supply curves.

Phase III is being conducted concurrently with Phase II. Phase III is collecting additional wind and solar data for use in developing a plan to integrate renewable energy resources into Hawaii's energy supply mix. The objectives are as follows:

- $\quad$ Collect at least a year's wind and solar data at selected locations and develop recommendations for an on-going renewable resource assessment program;

- Update resource supply curves for wind and solar developed under Phase II to reflect newly collected data; and

- Develop a plan to integrate renewable energy into Hawaii's energy supply mix.

In 1992, R. Lynette \& Associates (RLA) was selected as the consultant for Project 3 and work began in November.

\section{Project 3 Accomplishments}

In the first quarter of 1993, the choice of the best potential wind and solar project sites was narrowed. Land owners were asked if these projects would be in conflict with their intended use of the property. Permit and terrain requirements for the implementation of each technology at specific project sites were researched.

Resource areas for wind and solar were mapped and technology-specific constraints were developed for wind, solar thermal, and photovoltaics (PV) (based on utility-scale projects for electricity production) and were used to further eliminate sites with little potential. Biomass resources for energy crops were similarly mapped based on soil and climate conditions. A preliminary list of potential hydroelectric projects, including upgrades, was developed. For wind, solar, and biomass, additional elimination will occur based on discussions with land owners during the field surveys to determine their master plans for the land. For hydroelectric projects, public acceptance and environmental impact will play a large role in eliminating projects under consideration.

RLA obtained expansion plan information from each of Hawaii's electric utilities. This included revised transmission maps and information on repairs and replacements made by Kauai Electric following Hurricane Iniki. 
Based on the project list resulting from the field surveys, Zaininger Engineering Company, a subcontractor, held discussions focused on renewable energy with utility planners about their expansion plans and directly addressed concerns of system stability, transmission access and capacity, and the cost of transmission upgrades associated with each of the projects under consideration.

In January 1993, RLA began to formulate plans for field surveys, defining survey objectives, identifying and contacting the major land owners, utility representatives, developers, government officials, and environmentalists. The project list for potential renewable energy development was greatly refined based on information obtained. Initiated at the end of February, the field surveys concentrated on identifying suitable land for wind and solar projects, while potential locations for hydro, wave, and OTEC were evaluated on a limited basis. Potential biomass sites were based on identification of existing agricultural land. The field surveys were completed in early March, when RLA personnel met with Energy Division representatives to discuss preliminary impressions.

During the field surveys, some public acceptance concerns were addressed by speaking to county planners and officials; however, further research is required. These issues, as well as culturally sensitive issues, were analyzed for each of the projects on the list compiled by the field surveys.

In the second quarter, RLA began to develop the assessment plan. Preliminary project lists for wind, solar, biomass, hydroelectric, wave, and OTEC energy projects were compiled for each island. The site list was screened for environmental and cultural sensitivity. All available monitoring data for wind and solar resource assessment was reviewed to identify and acquire any data that will be useful in developing performance values for wind and solar projects. Owners of existing data sets were asked for copies. Where data was not publicly available for potentially valuable renewable energy sites, the locations were targeted for monitoring.

Near-term penetration limits for sources of intermittent power generation for each island were estimated, assuming utility operating practices remain unchanged, as follows:

$\begin{array}{lr}\text { ISLAND } & \text { LIMIT } \\ \text { Kauai } & 7 \mathrm{MW} \\ \text { Oahu } & 128 \mathrm{MW} \\ \text { Maui } & 18 \mathrm{MW} \\ \text { Molokai } & <1 \mathrm{MW} \\ \text { Lanai } & <1 \mathrm{MW} \\ \text { Hawaii } & 18 \mathrm{MW}\end{array}$


These limits were calculated using an arbitrary factor of $10 \%$ of the annual peak utility demand load forecast for 1995. In addition, these projects may be either limited by the existing local transmission capacity, or must account for the cost of transmission upgrades. The available transmission capacity of utility lines in the vicinity of all proposed intermittent projects was investigated. Projects larger than those defined by the penetration limits will be considered in order to account for factors such as changes in demand, more sophisticated utility operating procedures, and third party electricity sales.

RLA submitted the Draft Renewable Energy Resource Assessment Plan for approval in mid-June; the report described potential renewable energy project sites and a monitoring plan designed to allow adequate resource assessment to develop resource supply curves in Phase II. The Project Manager reviewed the report and asked for revisions which were made in the final report accepted in August.

The Phase II coordination meeting was held by telephone in mid-October to discuss the work plan and timeline for Phase II as well as the consultant's recommendations for the number and location of sites, and financial considerations, to be used in the development of resource supply curves for each technology.

Permission was obtained from the majority of the private land owners and the necessary county permits on each island were obtained. Unexpected permit requirements for federal and state lands resulted in a slight delay, but all necessary permits were received by October. Data collection began under Phase III to obtain a year's solar and wind data at these potential project sites. This data collection effort, using equipment installed at each site will continue over the next year. As noted above, Phase II work to develop resource supply curves, and Phase III work to collect additional data are proceeding concurrently.

Work was also initiated to compile the cost and performance data on renewable energy conversion systems. RLA will compile the most current cost and performance data for each of the renewable energy conversion technologies. They will use several performance models to facilitate accurate performance estimates, including a solar energy generation model developed for LUZ International, PV performance models used by Pacific Gas \& Electric, and wind energy performance models developed by RLA.

In addition, before year end, work began on analyzing and reducing existing renewable resource data. In many cases, this work was already completed by RLA in conjunction with work on other projects. Based on that data, and data from the vicinity of potential project sites, RLA is using a variety of specialized software to process resource data.

Finally, the Hawaiian Sugar Planters' Association solar data collected since 1975 was published. Emphasis was placed on data determined to be accurate based 
on instrumentation, calibration practices, and maintenance procedures. The data was summarized on a daily average basis for each month and year in which data was collected. Notes regarding data recovery rates, calibration, and resulting accuracy levels accompany each data set. The location of each of the operating stations was depicted on a map. This information is intended for distribution to developers and other interested parties.

As the on-site data gathering effort will not be completed until late in 1994, it will not be possible to include the results in the initial HES Project 7 integration runs. The resource supply curves developed from existing data will be used. The results of the monitoring will be included in the final report and used in subsequent planning efforts.

\section{PROJECT 4: DEMAND-SIDE MANAGEMENT (DSM) ASSESSMENT}

Project 4 Purpose and Objectives. DSM is any utility activity aimed at modifying the customer's use of energy to produce desired changes in demand. It includes conservation, load management, and efficiency resource programs. DSM offers the potential for lower utility bills and avoidance of major plant investments. Benefits are also possible in reducing the environmental impact of utility energy supply production and potential diversification of resources.

The State of Hawaii Public Utilities Commission has directed Integrated Resource Planning (IRP) which involves identification of the resources or mix of resources for meeting consumer energy needs in an efficient, reliable manner, and at the lowest reasonable cost. DSM is an essential IRP resource.

The DSM Assessment Project will develop a comprehensive assessment of Hawaii's demand-side resources. The work is divided into two phases. Barakat \& Chamberlin, Inc. (BCI), was selected as the consultant for the first phase of Project 4 in 1992. The Phase I work was completed in 1993. The Phase I objective was to:

- Develop a framework and format for end-use and DSM measures data bases;

- Identify data gaps and establish a work plan for collecting missing data; and

- Develop a DSM measure database.

Phase II got underway in October 1993. Neos Corporation (Neos) was selected from among four proposals to perform this work. The objectives for Phase II are: 
- Assess end-use energy consumption by island and sector, with an emphasis on the commercial sector to develop Hawaii-specific DSM program concepts;

- Develop a DSM assessment, characterization, and evaluation capability within the DBEDT Energy Division; and

- $\quad$ Collect data to fill data gaps identified in Project 1, Analytical Energy Forecasting Model, and in this project's work.

\section{Project 4 Accomplishments.}

In the first quarter of 1993, two major deliverables were received. The DSM Measure Database Framework and Format was defined for use in developing a demand-side management measure database for DBEDT. The report included an overview of the measure database and a step-by-step approach for developing database entries. It identified the key components of the database structure, specified the database framework and format, and provided examples of each database component. The End-Use Database Framework and Format provided the framework to be maintained within the ENERGY 2020 forecasting module.

Flow charts were completed to describe DSM-related functions of the ENERGY 2020 model. These charts were incorporated into the End-Use Database Framework and Format report.

The Technical Review Subcommittee on DSM/Forecasting of the Energy Policy Advisory Committee Integration Group met on February 25, 1993, and received a briefing on these two deliverables. No major changes resulted from this review.

Representatives from BCI, and the Project 1 (Analytical Energy Forecasting Model) subcontractor, SSI, met in mid-May with HES project managers to discuss estimating DSM potential. Energy usage and demand forecasts were developed for residential, commercial, industrial, and transportation sectors in ENERGY 2020 in Project 1. DSM measures will be screened against the forecast produced by the ENERGY 2020 forecasting model.

In discussing data issues, it was determined that it would be advisable to separate "military" from the rest of the commercial sector as military electricity sales on Oahu comprise $25 \%$ of the commercial sector electricity sales and may skew results if left in. The "military" segment is not subject to direct state control. It is also expected that provisions of the National Energy Policy Act of 1992 setting efficiency improvement goals for federal facilities will expedite military efforts to implement DSM. 
It was also determined that the industrial sector requires customized and site specific DSM and was not set as an immediate priority for Project 4. It was decided to concentrate on private commercial sector through the building prototype simulation project because it is the largest electricity consuming sector and offers the highest savings potential from DSM. It is possible that, in the future, if better data on the industrial sector becomes available, more specific DSM opportunities could be developed.

Phase I work continued over the remainder of the year and was completed in the fourth quarter with the delivery of the measure database, the data gaps memorandum, and a work plan for collecting additional data required.

A Phase II Initiation Meeting was held in Honolulu during the second week of November. This meeting set the course of the remaining work.

Work was initiated to develop building prototypes to be used in Phase II to simulate the effects of DSM program options on Hawaii's commercial building stock. A detailed identification of building types selected for prototype developrnent was completed in December.

\section{PROJECT 5: TRANSPORTATION ENERGY STRATEGY}

Project 5 Purpose and Objectives. This project is developing a transportation energy strategy. Hawaii's energy security would be improved by diversifying the fuels used for transportation and reducing dependency on imported fossil fuels. The transportation sector is currently the largest energy-consuming sector in Hawaii, accounting for $63 \%$ of the petroleum demand. Local production of transportation fuels and feedstocks could also improve Hawaii's economic security and provide jobs for Hawaii's people.

Transportation Energy Demand. Transportation planning has received a great deal of attention in Hawaii; however, energy concerns have not weighed heavily in transportation planning and energy demands have not been considered or quantified. The Transportation Energy Demand portion of this project is designed to provide a basis for management and planning. The objectives are as follows:

- $\quad$ Assess energy requirements of current and proposed county, state, and regional transportation plans, taking into account air, ground, and marine transport fleet characteristics, fuel consumption levels trends and projections;

- Develop a transportation energy demand profile; 
- Identify energy savings potential in each (air, ground, and marine) transportation sector; and

- Estimate the potential for fuel substitution by alternative fuels in each transportation sector.

Transportation Energy/Fuels Supply Development. Considerable activity in the area of alternative fuel production, demonstration, use and impacts has occurred and continues worldwide. In Hawaii, several studies, research projects, and demonstration projects on the production of fuels from biomass and the use of alternative fuels and electric vehicles have been carried out or are currently underway. The transportation energy supply portion of the summary will provide a basis for managing and planning transportation fuel supplies. The objectives are as follows:

- Describe Hawaii's existing and potential transportation fuels systems;

- Identify and quantify indigenous resources for production of fuels and transportation energy;

- Identify and discuss the most promising conversion technologies and possible energy and fuel production costs; and

- Develop an action plan for supplying transportation energy to meet future projected demand.

To integrate this work, policies and actions in the transportation sector to achieve overall goals of increasing energy security and efficiency of energy use, diversifying energy supply, enhancing stability, and maximizing local benefits will be developed. In addition, the optimum transportation fuel and energy mix and an implementation plan will be developed.

Parsons Brinckerhoff Quade \& Douglas, Inc. (PBQD), in association with the Hawaii Natural Energy Institute and Acurex Environmental, Inc., were selected in 1992 to develop the Transportation Energy Strategy.

\section{Project 5 Accomplishments.}

In the first quarter of 1993, drafts of a technical memorandum, Transportation Fuel Consumption: Existing and Future Baseline Conditions, and portions of Potential Use of Alternative Fuels in Hawaii's Transportation Sector, were received.

Fuel consumption by the transportation sector was calculated based $\mathrm{n} n$ available data. Relationships between transportation activities and fuel consumption were determined for ground, air, and marine transportation modes from 1981 to 1990 . Annual energy consumption by each transportation mode was 
summarized from tables of data collected under the State of Hawaii's energy reporting law (Chapter 486E, Hawaii Revised Statutes) by using a screening technique to separate transportation and non-transportation end uses. Fuel efficiency rates for ground vehicles, airborne passengers and cargo tons, and waterborne cargo tons for current or future years were obtained from or adjusted based on the Argonne National Laboratory Report, Forecast of Transportation Energy Demand through the Year 2010.

Data on statewide airport system plans and port master plans were obtained. Relationships between energy consumption and number of airborne passengers and between energy consumption and tonnage of waterborne cargo were determined.

In the second quarter, portions of the draft technical memorandums for estimating transportation energy savings potential and additional portions of the memo, Potential Use of Alternative Fuels in Hawaii's Transportation Sector, were received.

Additional memorandums, Energy Impacts of County and State Transportation Plans, Estimate of Transportation Energy Savings Potential, Potential Use of Alternative Fuels, Potential Transportation Energy and Fuels Systems, Indigenous Biomass Energy Sources for Transportation Energy and Fuels, and Description of Steps Towards the Best Alternative Fuel Production and Use Options for Hawaii were completed by the end of the year and are undergoing review by the Energy Division Staff and the Technical Review Subcommittee.

Work continues on to identify and evaluate transportation energy policies and actions and to develop implementation plans. The final report is also being completed, with expected delivery by February 1994.

\section{PROJECT 6: ENERGY VULNERABILITY ASSESSMENT REPORT AND CONTINGENCY PLANNING}

Project 6 Purpose and Objectives. This project will comprehensively assess Hawaii's vulnerability to energy supply disruptions. It will also evaluate the State's contingency planning to effectively contend with an energy supply disruption.

The objectives are:

- To conduct a comprehensive assessment of Hawaii's vulnerability to energy supply disruptions;

- To evaluate prospective industry/state emergency preparedness actions and acceptable levels of risk in view of potential vulnerabilities; and 
- To recommend initiatives and plans to enhance Hawaii's contingency planning and response capability.

Project 6 Accomplishments. James Bac, a member of the Energy Division's Planning and Policy Group specializing in energy emergency preparedness, was appointed co-manager of this Project, along with John Tantlinger.

Project 6 was scheduled to get underway in June, 1993, but, in the spring the Energy Division was informed of the opportunity to obtain funds for hazard mitigation relating to energy system vulnerability and energy emergency preparedness from the Federal Emergency Management Agency (FEMA), as part of the Hurricane Iniki hazard mitigation effort under the federal Stafford Act.

A plan for coordinating the approach to the vulnerability mitigation project to also meet the requirements of HES Project 6 was developed and discussed prior to the grant application. Participants in the development of the plan and grant application were Glenn Coplon, USDOE Office of Energy Emergencies and Federal Co-Manager for HES Project 6; Inja Paik, USDOE Emergency Program Development Office; Eileen Yoshinaka, USDOE Pacific Site Office; and Craig Zingman, USDOE Office of Energy Emergencies.

An application to FEMA to conduct the vulnerability mitigation project on an equal, cost-shared basis was subsequently developed and submitted. The application was later returned to the state with a request to revise the scope of work by including additional detail regarding specific hazard mitigation measures which may be recommended for implementation. It was also recommended that the project be divided into two phases with the assessment in phase I and the implementation of phase I recommendations in phase II.

Revisions were made consistent with FEMA's request and the application was resubmitted for FEMA's consideration.

Upon grant approval by FEMA, this project will begin as soon as possible.

\section{PROJECT 7: ENERGY STRATEGY INTEGRATION AND EVALUATION SYSTEM}

Project 7 Purpose and Objectives. Project 7 will integrate for implementation the findings of the overall HES program into a comprehensive state energy strategy. Recommended policy, legislative, and regulatory initiatives for implementation and evaluation will be developed.

The objectives are to integrate and synthesize the HES program into a final report. This will include facilitating the integration of information between the other six projects and inclusion of that information in the final report. The draft 
final report will be presented to the public to obtain feedback for inclusion in completing the final published report.

Based upon the work in the projects, the Energy Division will identify, assess and recommend the optimal public policy mechanisms (e.g., legislative, regulatory, or both) by which to implement a least-cost strategy for energy development in Hawaii. Existing energy policy and planning management frameworks will be used for synthesis, integration, implementation, and evaluation of policy and planning initiatives that will emerge from the component projects.

Project 7 will also develop, propose, implement, and evaluate policy initiatives and plans to formalize an energy strategy performance management system within State government; and policies and procedures to internalize energy externalities in Hawaii's regulated and non-regulated energy sectors.

Project 7 Accomplishments. The Energy Division staff began Project 7 when the initial draft of the overall HES Final Report outline was finalized in June 1992. The outline was included in the HES Program Guide in September 1992 and provided to all Project Managers and their consultants to assist them in developing a compatible final project report. Uncertainties regarding funding resulted in a decision to defer issuing an RFP for consultant assistance for Project 7 in 1992.

The funding issues were resolved in 1993 and a new scope of services and project schedule was completed in late February. The scope of services has evolved considerably since the original HES Proposal in November 1991. The work to be done by the consultant will focus on developing a Hawaii Energy Policy Integration Model using ENERGY 2020 and the use of the model to evaluate the effectiveness of various policy options. In addition, the consultant will develop, propose, implement, and evaluate policy initiatives and plans to formally adopt the model by developing plans and legislation to acquire needed data; and train the Energy Division staff in the use of the model.

The RFP was sent to over 150 consultants in mid-March. Only two responded. Systematic Solutions, Inc. (SSI), was selected as the consultant.

Due to the need for thorough coordination of the integration effort, SSI's proposal was staffed throughout the DBEDT Energy Division for comment. The resulting questions and instructions were forwarded to SSI for use in finalizing their scope of services.

SSI is developing a version of the ENERGY 2020 computer model, tentatively named HEPIM, or Hawaii Energy Policy Integration Model, for use in integrating and evaluating the projects of the HES Program.

Representatives of SSI met with HES Project Managers in a series of meetings from September 1 to 3 . The meetings identified the data and information to be 
produced by each project. SSI identified its preliminary data requirements and efforts are underway to collect that information.

A focus of the coordination effort has been on the interface between Projects 4 (DSM Assessment) and 7. A DSM Assessment Model will be developed by the Project 4 consultant. After much discussion and study, it was determined that an aggregating spreadsheet would be developed by the Project 4 consultant to pull out data on DSM programs and measures needed for evaluation of the impact on enduse and on the economy in Project 7.

Due to resource limitations, it was also decided that the Energy Division staff would develop the portion of this project related to the Externalities Cost/Benefit Assessment.

The contract was executed and work began in October. The initial focus was on calibrating the REMI economic model for use in ENERGY 2020.

Work also began on developing the electricity, gas and independent power producer sectors; and the oil refinery sector. Incorporation of Project 2 results also began, along with scenario development.

The schedule calls for initial model runs in June 1994 with final runs in August to allow incorporation of results into the draft final report.

\section{OVERALL HAWAII ENERGY STRATEGY PROGRAM ACCOMPLISHMENTS}

Hawaii Energy Strategy Management Team and Organization. The HES is a cooperative effort between the State of Hawaii Energy Division and the USDOE. To manage HES, the following organizational structure was established.

The Energy Program Administrator Maurice H. Kaya, is the Energy Division's HES Program Manager and Principal Investigator, and Jay Braitsch, Deputy Director, Office of Planning \& Environment is the USDOE's Program Manager.

The Energy Division HES Program Manager and his subordinate Program Coordinators and Project Managers manage the day-to-day activities of the program. The Energy Division designed the overall program in consultation with the USDOE. The Energy Division subsequently issued RFP's, received and evaluated the proposals, recommended their selection to the Director of DBEDT, and developed the details of contracts with the consultants selected. While working with the consultants on the execution of the projects, the Energy Division HES Project and Program Managers keep their corresponding Department of Energy Managers appraised of major activities. Department of Energy Managers provide guidance and recommendations as appropriate. (Figure 1, on the following page, depicts the HES Program Management structure which changed slightly since the 1992 report.) 


\section{Inter-Project Communication and Coordination.}

Energy Division Principal Investigator. The Energy Division Principal Investigator is responsible for the overall program. He selected Energy Division Program Coordinators and Project Managers. He oversees the consultant selection process and sign: contracts with the consultants on behalf of DBEDT. He sets overall policy, provides direction, and guidance.

Energy Division Program Coordinators. The Energy Division Program Coordinators continue to provide several means to assist the Project Managers and the consultants in coordinating their efforts. These include:

- Revision of the Hawaii Energy Strategy Program Guide;

- A periodically updated Critical Path Method (CPM) chart;

- $\quad$ Conducting HES Task Force Meetings approximately every five - seven weeks and issuing minutes;

- Memorandums providing guidance for specific issues; and

- Consultation.

Hawaii Energy Strategy Public Participation Program. The HES Public Participation Program is designed to gain public input and support for the program. It includes direct public participation and a public information prograin. Direct public participation includes two elements -- Technical Advisory Groups under the auspices of the EPAC and formally established opportunities for participation by the general public.

Technical Advisory Groups. Technical Advisory Groups are based on the EPAC and its Integration Group (IG) which were established during the development of the Hawaii Integrated Energy Policy. The EPAC and IG are comprised of members of Hawaii's "energy community", including energy companies, utilities, environmental groups, and state and county government organizations. The EPAC continues to serve as an advisory body to the Director of DBEDT in the Director's role as Hawaii's Energy Resources Coordinator. Subcommittees were formed by project groups for periodic review of the progress and results of each project.

The Technical Review process was set up at a meeting of the IG on September 14, 1992. Subcommittees were formed by project groups for periodic review of the progress and results of each project. The following subcommittees were formed: 


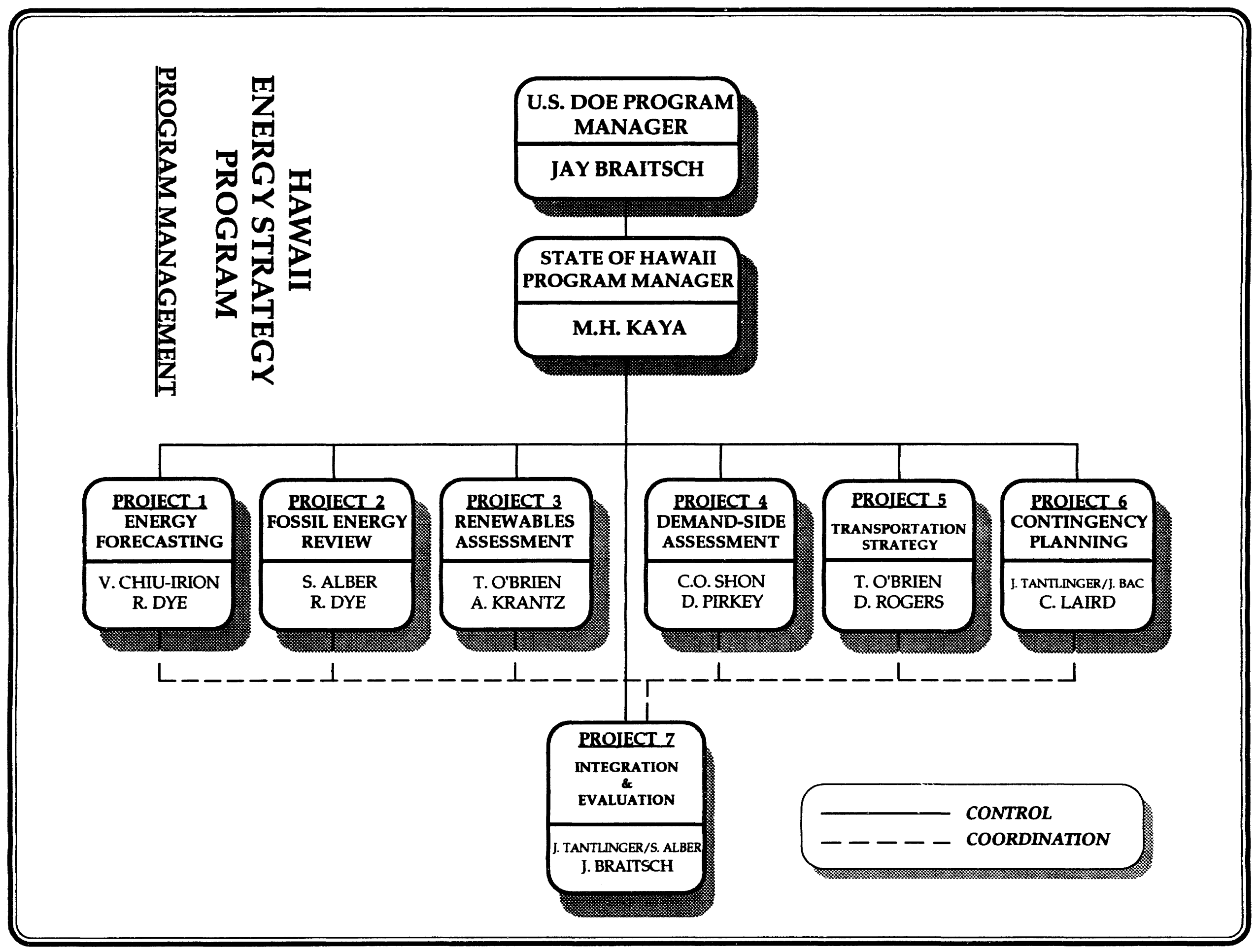


- $\quad$ Forecasting and Demand-Side Management. (Projects 1 and 4)

- $\quad$ Fossil Fuels and Renewable Energy. (Projects 2 and 3)

- Transportation. (Project 5)

- $\quad$ Energy Emergency Preparedness. (Project 6)

As noted above in the discussions of each individual project, the Technical Review subcommittees have been active in the review of the work of the Projects.

a. Energy Emergency Preparedness. Committee members were updated in May on the status of HES Project 6 (Energy Vulnerability Assessment and Contingency Planning), including efforts to accomplish the objectives of this project under the FEMA Hazard Mitigation Program. The members agreed to this approach.

The Energy Emergency Preparedness Technical Review Sub-committee reviewed and commented on the proposed Project 6 scope of services in July.

b. Fossil Energy/Renewable Energy. In the first quarter of 1993, the drafts of five chapters produced by Project 2 (Fossil Energy Review) comprising Overview of Fossil Fuels, were provided to the Fossil Fuels/Renewables Technical Review Subcommittee. Copies were also provided to Richard Dye, the USDOE project manager. USDOE, HECO, and the Pacific International Center for High Technology Research members provided comments.

In June, members of the Subcommittee were sent copies of Project 2 drafts, Fossil Energy in Hawaii and Assessment of Coal Technology Options and Implications for the State of Hawaii. Comments were received from HECO. Richard Dye of USDOE provided a comprehensive set of comments.

c. DSM/Forecasting. The Technical Review Subcommittee on DSM/Forecasting met on February 25, 1993, and received a briefing on the DSM Measure Database Framework and Format and the End-Use Database Framework and Format developed under Project 4 (DSM Assessment). No major changes resulted from this review.

The initial draft forecast prepared under Project 1 (Analytical Energy Forecasting Model) was presented to the Subcommittee members in early May. Subcommittee members from HECO and The Gas Company were represented by their forecasting specialists who reacted favorably to the forecast and offered additional data to help refine it.

Public Involvement. Public involvement is based upon the introductory HES Workshop held on October 23, 1992. The Workshop provided the general 
public with information about the HES program and invited comments, ideas, and suggestions for additional public participation.

Work is underway in preparation for a second HES Workshop to be held on January 11, 1994.

Public Information Program. The HES public information program includes news releases on HES program and individual projects; articles for business, trade, and general interest magazines; and speakers for various interested groups.

An article outlining the HES program was published in the June 6, 1993, issue of the Honolulu Advertiser.

In addition, Energy Division staff members provided preliminary information from the various HES projects' work to the subcommittee $\dot{s}$ of the Legislature's Energy and Environmental Forum, which greatly assisted in the work of those subcommittees.

Cooperative Agreement. The Cooperative Agreement with the U.S. Department of Energy was amended at the beginning of March 1993. The amendment provided the additional $\$ 750,000$ which had been appropriated for Phase II.

Meetings with USDOE Project Managers. The Energy Program Administrator Maurice Kaya, provided the USDOE Program Manager, Jay Braitsch, with an updated status report on HES' progress during meetings in Washington in March and September. USDOE inputs and recommendations were provided during these meetings.

At the March meeting, the proposed approach for Project 7 (Integration and Evaluation System) was also discussed. The September meeting included discussions of the new approach to Project 6 (Energy Vulnerability Assessment and Contingency Planning), plans for a Program Management meeting in Honolulu in conjunction with the second HES Workshop in January 1994.

Report Distribution Increased. In early January, we initiated provision of copies of the HES Annual Report and HES Quarterly Reports to Project Managers, consultants, and members of the IG to keep them better informed as to progress in the program. In particular, IG members, who are not direct participants in the program, will be better informed to perform their role as technical advisors on the Technical Review Subcommittees.

Critical Path Method (CPM) Chart. A new version of the chart as of April 1, 1993, was completed. The chart was reproduced and distributed in early April. Subsequent updates were made about every two months with working copies distributed to each Project Manager. 
HES Workshop Proceedings. The Proceedings of the Hawaii Energy Strategy Workshop was completed in January 1993 and sent to HES Workshop participants, to consultants, to members of the Integration Group, and to Energy Division and USDOE Project Managers in February. Copies were also placed in public libraries throughout the state.

HES Training Schedule. A common training schedule was developed to coordinate training of Energy Division staff as part of the HES objective to strengthen staff expertise through skills acquisition and improvement. Examples of training include the Fossil Energy in Hawaii Seminar held in May (see above) and training on utility finance held in mid-July.

Energy and Environmental Summit. The State Legislature sponsored an Energy and Environmental Summit which was held on October 8, 1993. To prepare for the summit, citizen groups were established to examine issues and develop proposed legislation. Energy Division staff members participated on Energy Supply, Energy Demand, Transportation Energy, and Education subcommittees. This participation included presentations to the committees on the HES program and information available to this point. The information developed by the HES program so far proved particularly useful to the subcommittees in developing their ideas for legislation.

\section{HES STATUS ASSESSMENT AND FORECAST}

As noted above, the Interim HES Workshop is planned for January 11, 1994. A Project Review meeting is also scheduled for January 12, 1994, involving meetings between USDOE Energy Division Project Managers and Energy Division Project Managers.

The overall HES remains on schedule. Delays in individual projects should not affect program completion. As noted in last year's report, the program as a whole varies somewhat from the originally proposed schedule since the proposal envisioned the program starting in November 1991, but the Cooperative Agreement was not signed until March, 1992. In addition, due to delays in obtaining necessary state approvals to contract, changing contracting procedures, and taking more time than anticipated to complete the consultant selection and contracting process, many projects got underway late. Schedules have been revised due to data collection problems, permitting delays, and other problems; nevertheless, we believe the revised schedules will allow completion prior to the end of 1994 as originally planned. 

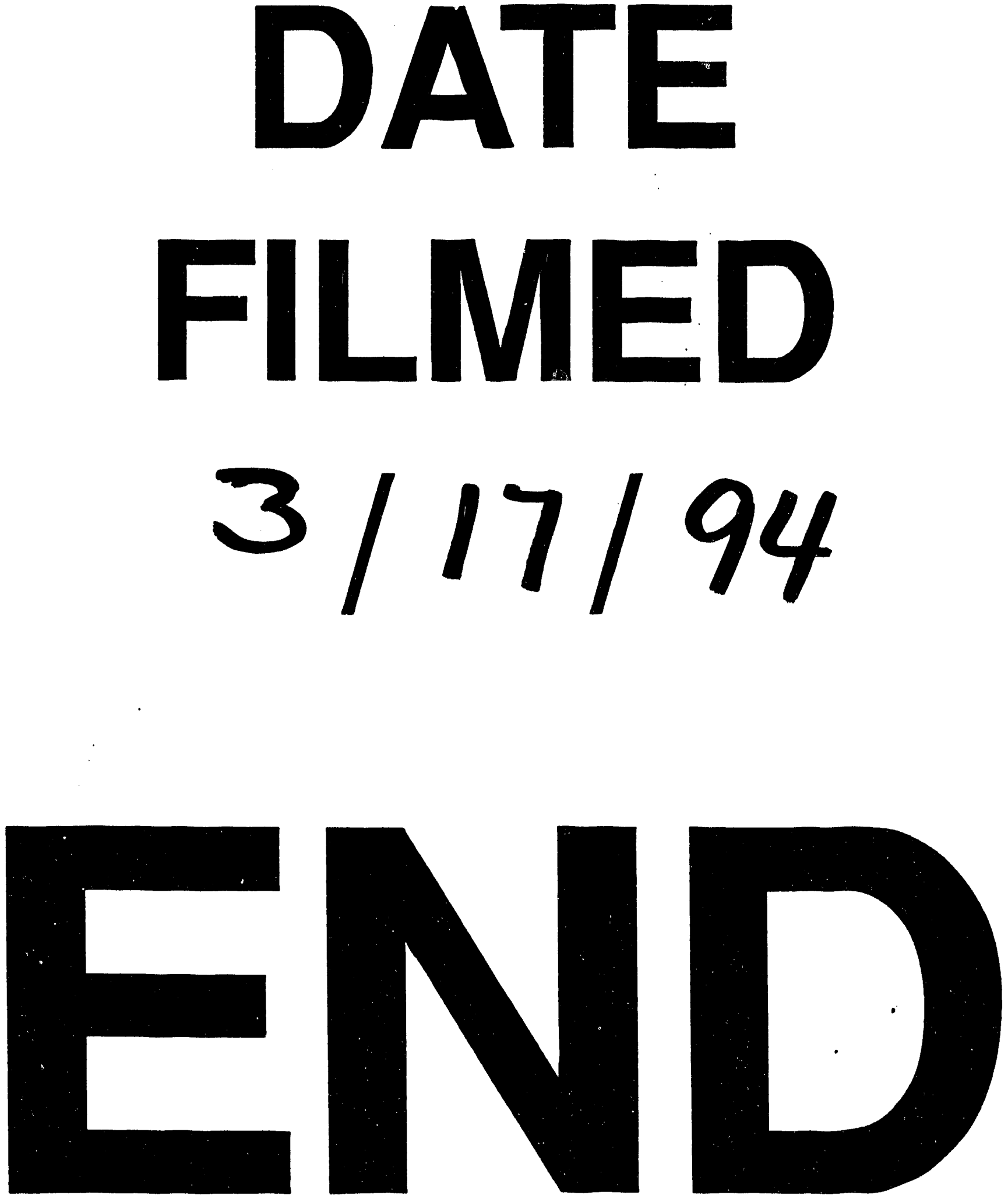